\title{
THE EFFECT OF 12-WEEK-LONG NORDIC WALKING EXERCISE ON BODY COMPOSITION, CHANGES IN LIPID AND CARBOHYDRATE METABOLLSM INDICES, CONCENTRATION OF SELECTED ADIPOKINES AND CALCIDIOL IN HEALTHY MIDDLE-AGED WOMEN
}

\author{
Łukasz Tota, 1, A, B, C Wanda Pilch, 2, D, E, F Anna Piotrowska, 2, A, D Tomasz Pałka, 1, E \\ Paweł Pilch ${ }^{3, E}$ \\ ${ }^{1}$ Department of Physiology and Biochemistry, Faculty of Physical Education and Sport, University of Physical Education, Kraków, Poland \\ ${ }^{2}$ Department of Cosmetology, Faculty of Rehabilitation, University of Physical Education, Krakow, Poland. \\ ${ }^{3}$ Rydygier Memorial Hospital, Kraków, Poland \\ ${ }^{\text {A }}$ Study Design; ${ }^{\mathrm{B}}$ Data Collection; ${ }^{\mathrm{C}}$ Statistical Analysis; ${ }^{\mathrm{D}}$ Manuscript Preparation; ${ }^{\mathrm{E}}$ Funds Collection
}

\author{
Address for corpespondence: \\ Łukasz Tota \\ al. Jana Pawła II 78 \\ Kraków 31-571, Poland \\ E-mail: lukasztota@gmail.com
}

\begin{abstract}
Ahstract Research objective. This study aimed at analysing the changes in the level of somatic indicators, the secretion profile of selected adipokines, carbohydrate and lipid metabolism indices and calcidiol concentration after a 12-week-long nordic walking (NW) exercise in middle-aged women.

Research material and methods. The study included 13 women aged $45.5 \pm 4.2$ years who participated in a 12-week-long NW exercise, 3 times a week, 90 minutes each. Each of the women had individually determined workout intensity zones which were monitored based on the heart rate. Prior to the exercise programme and after it, somatic traits were assessed and blood was sampled in order to make biochemical analyses.

Results. In the examined women, a decrease in mean body weight by $2.5 \mathrm{~kg}$ and a reduction in fat mass (FM), on average by $3.8 \mathrm{~kg}$ (i.e. $4.6 \%$ ), coupled with an increase in lean body mass (LBM) by $1.3 \mathrm{~kg}$, were observed after 36 workout units. A significant decrease in TC, LDL-C and TG concentrations and no changes in HDL-C concentration occurred after the exercise, which contributed to lowered atherogenic index of plasma (AIP) and atherosclerosis risk index (ARI).

Conclusions. Individualised and regular physical activity in the form of NW had a protective effect on the body, resulting in improved body composition, adiponectin secretion profile, lipid and carbohydrate metabolism, and calcidiol concentration in middle-aged women.
\end{abstract}

Key Worlds health-related training, nordic walking, middle-aged women, exercise biochemistry 


\section{Introduction}

Health-related training being conducted in various forms which allows maintaining the proper health at any age is an element of life still often underestimated by many people used in the prevention and treatment of metabolic civilisation diseases (Singh, Purohit, 2012). Scientists clearly indicate the physical activity as one of the main factors that reduce the risk of obesity, type 2 diabetes, ischaemic heart disease, and arterial hypertension (Katzmarzyk, 2010). Research data suggest that increased physical activity in middle-aged people may contribute to a reduction in mortality (Kokkinos, Myers, 2010) at a level comparable to smoking cessation (Byberg, Melhus, Gedeborg, Sundstrom, Ahlbom, 2009).

In addition, sedentary lifestyle, being the result of progress in development of civilisation, promotes the increased deposition of visceral adipose tissue which is a source of hormones and adipokines. The increase of adipocyte volume affects the changes in adipokine secretion (decreased adiponectin production and increased leptin secretion). A consequence of these changes is development of insulin resistance, type 2 diabetes, and cardiovascular diseases (Chudek, Adamczyk, Nieszporek, Więcek, 2006). On the other hand, adipocytes produce adiponectin which plays a key role in the stimulation of glucose consumption and the oxidation of fatty acids (Combs, Berg, Obici, Scherer, Rossetti, 2001). Numerous studies have shown that also ghrelin-which stimulates food ingestion-is responsible for normal body mass level (Mackelvie, Meneilly, Elahi, Wong, Barr, 2007; Wren, Small, Ward, Murphy, Dakin, 2000).

Many studies have emphasised that an appropriate vitamin $\mathrm{D}$ level in the body is necessary to maintain the structural integrity and function of muscles (Polly, Tan, 2014). Vitamin D, binding the intracellular and membrane receptors (VDR) of muscle cells, stimulates the synthesis of about 200 different proteins. Genes, being stimulated by vitamin $\mathrm{D}$ with its receptor, produce growth factor proteins that regulate the proliferation of satellite muscle cells and stimulate their maturation and differentiation to mature, fast-twitch (type 2) muscle fibres, being responsible for muscle strength, contraction speed and mass (Pojednic, Ceglia, 2014).

Nordic walking is a safe form of physical recreation for people of any age, being of endurance exercise nature, extensively involving - compared to traditional walking - the muscle groups of upper extremities. While maintaining the correct technique of walking during the NW exercise, $90 \%$ of muscles is being involved, while in the case of normal walking the number of involved muscles decreases to about 70\% (Morgulec-Adamowicz, Marszałek, Jagustyn, 2011). Physical exercise programmes involving pole walking are used to counteract obesity, contributing this way to negative energy balance.

For middle-aged women, there are still no specific guidelines to create the training programmes involving the NW exercise, the regular and thorough performance of which would contribute to improved fat and carbohydrate metabolism and changes in adiopkine secretion profile, including calcidiol concentration.

In the literature, there is a number of reports that confirm the positive effect of NW exercise on human health (Tschentscher, Niederseer, Niebauer, 2013). However, the mechanism of the beneficial effect of physical exercise, its intensity and duration on fat and carbohydrate metabolism and changes in adipokine concentration is still the subject of many studies (Hagner, Hagner-Derengowska, Wiacek, Zubrzycki, 2009; Song, Yoo, Choi, Kim, 2013, Lubkowska, Dudzińska, Bryczkowska, Dołęgowska, 2015a). The selection of physical activity intensity, frequency and type, which would optimally affect the above changes, is also discussed.

This study aimed at analysing the changes in the level of somatic indicators, the secretion profile of selected adipokines, carbohydrate and lipid metabolism indices after a 12-week-long NW exercise in middle-aged women 
from a rural environment. Taking into account the fact that the workouts were performed in an open area in spring (March-May), also the changes in calcidiol concentration were analysed.

\section{Material and methods}

\section{Research plan}

The research project was approved by the Bioethics Committee of the Regional Medical Chamber in Cracow (137/KBL/OIL/2013). Joining the research programme, each of the women had to meet the following inclusion criteria: medical certificate stating the absence of medical contraindications to perform physical exercises, not using pharmacological hypotensive, hypolipemiant and hormonal therapy and using dietary supplements in a period of at least 4 weeks preceding the study, and not drinking alcohol in a period of at least 2 weeks preceding the study and during it. The female subjects were also asked to maintain their normal nutritional habits. The level of physical activity was determined using an IPAQ-SF (International Physical Activity Questionnaire-Short Form) survey questionnaire (Biernat, Stupnicki, Gajewski, 2007) that concerns the previous and current physical activity. The women with declared earlier physical activity at the level of $534 \pm 38 \mathrm{MET}$ (Metabolic Equivalent) minutes/week were included in the study.

A 12-week-long health-related training lasting from March to May involved the women who participated three times a week in the activities with the NW exercise, 90 minutes each. During the whole training programme, each of the women took part in 36 workouts. Prior to the exercise programme and after it, somatic traits of the female subjects were assessed and blood was sampled in order to make biochemical analyses.

\section{Characteristics of the subjects}

The study included 13 women from Małopolskie Province who agreed in writing to take part in the research programme. During the project, the women did not participate in any other organised and regular physical activity. The characteristics of their somatic indicators is presented in detail in Table 1.

\section{Measurement of anthropometric parameters}

The measurement of somatic traits in the subjects was made one day before and one day after the training period. The subjects did not suffer from any diseases that would affect the water and electrolyte balance; $2-3$ hours prior to the measurement of body structure, they did not perform any physical exercise. The following parameters were measured: body height $(\mathrm{BH})$, body mass $(\mathrm{BM})$, fat mass $(\mathrm{FM})$, body fat percentage $(\mathrm{F} \%)$, and lean body mass (LBM).

The body structure was determined by electrical bio-impedance technique using a Jawon Medical IOI 353 body composition analyser (Korea), body height was measured with a Martin-type anthropometer (USA) accurate to $0.1 \mathrm{~cm}$.

\section{Chapacteristics of the nordic walking exercise}

Workouts took place in the morning hours in an open area with three instructors. Prior to the activity, the women took part in 3 instructive sessions on mastering the proper technique of pole walking. The length of NW poles was individually matched to the body height of the subjects (Morgulec-Adamowicz, 2011). 
Each workout session was composed of three parts: a warm-up (15.0 \pm 2.0 minutes), the main workout ( $60.0 \pm 4.2$ minutes), and a final part (15.0 \pm 1.2 minutes). The warm-up consisted of a set of stretching exercises and elements that build the proper technique of pole walking. In the main workout, aerobic exercises prevailed, being performed as continuous and interval walking in a varied terrain. In the final part, there were cooling down exercises.

During the physical activity, all women used heart rate monitors Polar RS400, (Finland). In the main part of the workout, the female subjects were supposed to keep the individually determined HR value $\left( \pm 4\right.$ beats $\left.\cdot \mathrm{min}^{-1}\right)$ so that the intensity of exercises in the study group was diversified. The intensity of the main part was also controlled by three instructors.

The 12-week-long training was divided into 34 -week-long mesocycles of different intensity. During the first mesocycle, the intensity of walking in the main part corresponded to $50 \pm 1.2 \% \mathrm{HRmax}$, whereas during the second mesocycle to $60 \pm 2.3 \%$ HRmax, while being $65 \pm 3.1 \%$ HRmax in the third one. Maximum heart rate (HRmax) was estimated according to the following formula: HRmax $=211-0.64 \cdot$ age (in years) (Nes, Janszky, Wisløff, Støylen, Karlsen, 2013) which corresponded to $181.9 \pm 2.7$ beats $\cdot \mathrm{min}^{-1}$ for the study group.

\section{Biochemical analyses}

One day before the training programme and one day after it, blood was drawn from a vein in the cubital fossa of all fasting subjects by a laboratory diagnostician in accordance with applicable standards. Blood was collected in Vacutainer ${ }^{\mathrm{TM}}$ blood collection tubes with EDTA. The following parameters were determined in blood plasma: total cholesterol - TC, HDL cholesterol - HDL-C, and triglycerides - TG, glucose, insulin, leptin, ghrelin, adiponectin and 25-hydroxyvitamin D (25(OH)D).

\section{Determination of lipid metabolism indices}

TC, HDL-C, TG levels were determined by the enzymatic method from Abbott Laboratories on an Architect ci8200 integrated serum/plasma analyser system, Abbott Laboratories, Abbott Park, IL (USA).

Low-density lipoprotein (LDL-C) level was calculated from the Friedwald formula (Friedewald, Levy, Fredrickson, 1972): LDL-C $\left[\mathrm{mmol} \cdot \mathrm{l}^{-1}\right]=\mathrm{TC}\left[\mathrm{mmol} \cdot \mathrm{l}^{-1}\right]-\mathrm{TG}\left[\mathrm{mmol} \cdot \mathrm{I}^{-1}\right] / 2.2-\mathrm{HDL}\left[\mathrm{mmol} \cdot \mathrm{I}^{-1}\right]$. The LDL-C level was calculated assuming that the concentration of TG is below $4.6 \mathrm{mmol} \cdot \mathrm{I}^{-1}$

Triglyceride (TG) level was determined by the triglyceride test from Abbott Laboratories on an Architect ci8200 integrated serum/plasma analyser system, Abbott Laboratories, Abbott Park, IL (USA).

\section{Determination of atherosclerposis risk index}

Atherosclerosis risk index (ARI) was calculated from the following formula: ARI = TG/HDL-C, where: TG triglycerides (ml/dl), HDL-C - high-density lipoprotein expressed in ml/dl (Luc, Bard, Ferrieres, Evans, Amouyel, 2002).

\section{Determination of the level of carhohydrate metabolism indices}

The determination of insulin concentration was made by the electrochemiluminescent method (ECLIA) using a Cobas analyser, Roche Diagnostics (USA).

The glucose concentration in venous blood serum was determined by the hexokinase method using a Cobas analyser, Roche Diagnostics (USA). 


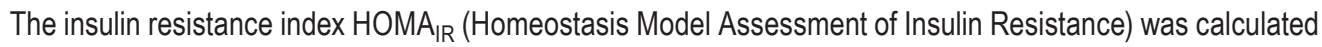
from the following formula (Matthews et al., 1985): $\mathrm{HOMA}_{\mathrm{IR}}=\mathrm{C}_{\mathrm{INS}}(\mu \mathrm{U} / \mathrm{ml}) \cdot \mathrm{C}_{\mathrm{GLUC}}(\mathrm{mmol} / \mathrm{l}) \cdot 22.5$, where: $\mathrm{C}_{\text {INS }}$ - insulin, $\mathrm{C}_{\mathrm{GLUC}}-$ glucose.

The atherogenic index of plasma (AIP) was calculated based on the following formula (Dobisova, 2004): AIP $=\log (T G / H D L-C)$, where: $T G-$ triglycerides (mmol/l), HDL-C - high-density lipoprotein expressed in mmol/l.

\section{Determination of the level of selected adipokines}

The determination of ghrelin, leptin and adiponectin concentrations was made by the immunoenzymatic method from Phoenix Pharmaceuticals (USA), leptin ELISA assay from DRG International Inc. (USA), and adiponectin ELISA assay from Mediagnost $\mathrm{GmbH}$, respectively (Germany).

\section{Determination of the level of 25-hydroxyvitamin D (25(OH)D)}

The concentration of $25(\mathrm{OH}) \mathrm{D}$ was determined in blood plasma by the immunoenzymatic method using a vitamin $D$ test from from DRG International Inc (USA).

\section{Methods of statistical analysis and ways of presenting research findings}

Research findings are presented as arithmetic means and standard deviations. The goodness of fit of the distribution of indicators being evaluated with the normal distribution was verified with the Shapiro-Wilk test. Changes in the concentration of biochemical indices being evaluated as affected by the training (normal distribution) was verified with the t-Student test for dependent variables. The analysis of relationships between the variables being examined was made using the Pearson's linear correlation. The statistical analysis of the research findings was performed with Statistica 10.0 software package for Windows from Statsoft.

The significance level of differences for all analysed indicators was considered statistically significant at $a \leq 0.05$.

\section{Results}

When starting the workouts with NW, the female subjects were characterised by normal body composition. After the training, a significant decrease in BM, FM and F\% and a significant increase in LBM were observed (Table 1).

Table 1. Characteristic of somatic indicators in the examined women

\begin{tabular}{lccc}
\hline \multicolumn{1}{c}{ Measurements } & Baseline & Post 12 weeks & $p$ \\
\hline Age (years) & \multicolumn{2}{c}{$46.0 \pm 4,2$} & - \\
BH (cm) & \multicolumn{2}{c}{$164.9 \pm 5.4$} & - \\
BM (kg) & $63.8 \pm 7,2$ & $61.3 \pm 5.8^{*}$ & 0.0001 \\
LBM (kg) & $43.7 \pm 3,2$ & $45.0 \pm 3.1^{*}$ & 0.04 \\
FM (kg) & $20,1 \pm 3,1$ & $16.3 \pm 2.9^{*}$ & 0.03 \\
F (\%) & $30.9 \pm 4.0$ & $26.3 \pm 2.9^{*}$ & 0.02 \\
\hline
\end{tabular}

$\mathrm{BH}$ - body height; $\mathrm{BM}$ - body mass, LBM - lean body mass, $\mathrm{FM}$ - fat mass, $\mathrm{F} \%$ - fat percentage, ${ }^{*} \mathrm{p}<0.05$ 
Before the training programme, mean TC, HDL-C, LDL-C and TG concentrations in all female subjects were within normal ranges. After the training, a significant decrease in TC, LDL-C and TG concentrations and no changes in the concentration of HDL-C were observed. These alterations contributed to a reduction in AIP and ARI (Table 2).

The mean glucose concentration in the female subjects prior to the training programme exceeded the accepted limit of $5.5 \mathrm{mmol} / \mathrm{L}$, (glucose levels being within the upper limits of reference values were recorded in $60 \%$ of the subjects, while in other women the glucose concentration was above the normal range). The insulin concentration was within the normal range in all subjects. After a 12-week-long training, a decrease in the glucose concentration to standard values was observed in the women with its increased level, as well as a decrease in its concentration in other female subjects. A significant decrease in the insulin concentration contributed to a reduction in $\mathrm{HOMA}_{\mathrm{IR}}$ index (Table 2).

Table 2. Characteristics of blood biochemical indices in the examined women

\begin{tabular}{lccl}
\hline \multicolumn{1}{c}{ Measurements } & Baseline & Post 12 weeks & p \\
\hline TC (mmol/l) & $5.0 \pm 0.4$ & $4.7 \pm 0.5^{*}$ & 0.04 \\
HDL-C (mmol/l) & $1.6 \pm 0.3$ & $1.6 \pm 0.3$ & 0.11 \\
LDL-C (mmol/l) & $2.9 \pm 0,7$ & $2.5 \pm 0,6^{*}$ & 0.002 \\
TG (mmol/l) & $1.3 \pm 0,5$ & $1.0 \pm 0,4^{*}$ & 0.002 \\
AIP & $-0.11 \pm 0.18$ & $-0.24 \pm 0.17^{*}$ & 0.0007 \\
ARI & $0.85 \pm 0.4$ & $0.62 \pm 0.24^{*}$ & 0.004 \\
Glucose (mmol/l) & $5.8 \pm 0,5$ & $4.6 \pm 0.6$ & 1.29 \\
Insulin $(\mu \mathrm{U} / \mathrm{ml})$ & $10,4 \pm 1,6$ & $8.8 \pm 1.6^{*}$ & 0.01 \\
HOMA IR $_{\text {Adiponectin }(\mathrm{ng} / \mathrm{ml})}$ & $2,7 \pm 0,5$ & $1.8 \pm 0.3^{*}$ & 0.0007 \\
Ghrelin $(\mathrm{ng} / \mathrm{ml})$ & $33.9 \pm 12,8$ & $41.8 \pm 12.5^{*}$ & 0.003 \\
Leptin $(\mathrm{ng} / \mathrm{ml})$ & $58,2 \pm 10.0$ & $22,1 \pm 9,5^{*}$ & 0.03 \\
Calcidiol $(\mathrm{ng} / \mathrm{ml})$ & $14.6 \pm 3,7$ & $10,6 \pm 2.4^{*}$ & 0.0001 \\
\hline
\end{tabular}

AIP - atherogenic index of plasma, ARI - atherosclerosis risk index, $\mathrm{HOMA}_{\mathbb{R}}$ - insulin resistance index.

After the training programme, a significant increase in the concentration of adiponectin and ghrelin, as well as a significant decrease in the leptin concentration, was observed in the female subjects (Table 2).

The baseline concentration of calcidiol in the female subjects was not within reference normal range $(>30 \mathrm{ng} / \mathrm{ml})$. The training performed in an open area contributed to its significant increase but the mean value of its concentration was still below the recommended limits (Table 2).

\section{Discussion}

The unique character of this study results from the analysis of changes in many indicators being responsible for carbohydrate and lipid metabolism and body composition as affected by individually determined training loads. The workouts were carried out in spring (March-May), which could contribute to more intensive synthesis of calcidiol in the skin and lead to an increase in its blood concentration (which was taken into account in the research methods).

Physical exercise, depending on its character, induces a number of phenotypic and physiological changes which include mitochondrial biogenesis, transformation of muscle fibres, improvement of insulin sensitivity and 
cytoprotection (Steinbacher, Eckl, 2015), as well as intensification of fatty acid oxidation in muscles, and modulation of the activity of many enzymes and development of the network of blood vessels (Macaluso, De Vito, 2004). With ageing and sedentary lifestyle, many adverse somatic alterations are being observed, the manifestation of which is, among others, reduced LBM and increased body fat level (Drygas, Jegier, 2003). Various studies have confirmed the effectiveness of regular physical activity in the fight against overweight and obesity in older people. However, the effectiveness of physical workouts being carried out depends largely on the exercise structure, duration and its intensity (Song et al., 2013, Lubkowska et al., 2015a), as well as - as shown by the most recent studies - on an adequate body level of vitamin D (Polly, Tan, 2014).

The results of the studies conducted so far have confirmed that the physical activity in the form of NW exercise being regularly applied may contribute to positive changes in the body build of the perimenopausal women who lead a sedentary lifestyle (Song et al., 2013; Mikalacki, Rajdo, Cokorilo, Korovliev, Smajic, 2012). When preparing the training loads for the participants of physical activities with the NW exercise, a particular importance was attributed to its intensity and individualisation. In the present study, the intensity of the main part of the workout was directed towards the dominance of fat metabolism in physical exercise energetics.

A consequence of the training programme being carried out in such a way was a decrease in BM by nearly $2.5 \mathrm{~kg}$, as well as a reduction in body fat mass by $4.6 \%$ with a simultaneous increase in LBM by nearly $1.3 \mathrm{~kg}$. Similar reduced $\mathrm{BM}$ and $\mathrm{F} \%$ values have been obtained by Mikalacki et al. (2012) who applied a similar training programme in the women aged $58.5 \pm 6.9$ years. The 12-week-long training plan being applied by them and carried out 3 times a week in the form of physical activities with the NW exercise with increasing intensity, from $60 \%$ to $80 \% \mathrm{HRmax}$, in obese women resulted in the reduction of BM by $3.72 \mathrm{~kg}$ and the decrease of $\% \mathrm{~F}$ by $4.28 \%$.

An important factor influencing the changes in lipid metabolism at rest and during physical exercise is an age-related increase in body mass, a decrease in aerobic capacity and a reduction in fatty acid metabolism rate (DeNino, Tchernof, Dionne, Toth, Adres 2001; Horowitz, Klein, 2000). In the present study, a significant decrease in the TG concentration was observed as affected by a 12-week-long NW exercise. Many studies have shown that the TG concentration $>1.7 \mathrm{mmol} / \mathrm{l}$, obesity, arterial hypertension and type 2 diabetes are the most common factors accompanying the ageing process (Reznik, Morello, Pousse, Mahoudeau, Fradin, 2002). For many authors, the increased TG level is a more important risk factor for atherosclerosis than the increased concentration of LDL-C (Nilsson, Ohrvik, Lonnberg, Hedberg, 2009). In the study by Hagner et al. (2009), after a 12-week-long NW exercise in pre-, peri- and postmenopausal women, significant positive effects being related to changes in body composition, decreased TC. LDL-C and TG concentrations, and increased HDL-C concentration have been observed. In the present study, no changes in the HDL-C concentration were observed Such a difference in the changes is likely due to the selection of a form of physical activity, amount and intensity of undertaken physical workout, and baseline concentration values of respective lipid profile components in the female subjects.

Lipid profile disorders are one of the factors that increase the risk fo developing atherosclerosis (Kozak-Szkopek, Baraniak, Mieczkowska, 2006). Studies have shown the presence of a strong relationship between increased plasma TG level and increased atherosclerosis development. Due to these relationships and to determine the risk for developing atherosclerosis in the examined group of women, atherosclerosis risk index - TG/HDL-C (Luc et al., 2002) - and atherogenic index of plasma (Dobisova, 2004) were introduced into the study. In the present study, a significant change in the ARI and AIP values were obtained as affected by the NW exercise, just as in the study by Haskell, Lee, Russell, Powell, Blair (2007). Additionally, AIP was negative, both during the first and the 
second measurement, which indicates a low level of risk for developing atherosclerosis in the examined group of women.

A significant worsening of carbohydrate metabolism is observed with age, resulting in lowered glucose tolerance due to increased insulin resistance, as well as to increased insulin secretion (Scheen, 2005). Many authors have emphasised a positive effect of regular physical workout on improving the glucose tolerance and preventing the development of type 2 diabetes in the subjects at any age (Perk, De Backer, Gohlke, Graham, Reiner, 2012). In the present study, normal insulin concentration values were observed during the first and the second measurement in the female subjects. The statistical analysis being applied showed a significant decrease in the insulin level and insulin resistance index $\left(\mathrm{HOMA}_{\mathrm{IR}}\right)$ after the NW exercise. The results obtained in the present study with respect to changes in glucose and insulin concentrations and $H O M A_{\mathbb{R}}$ index as affected by the NW exercise and negative correlations between these indicators and the changes in body fat mass as affected by the workouts have been confirmed by the studies of other authors (Hu, Pekkarinen, Hanninen, Tian, Guo, 2001). In the study by Matthews et al. (1985), normal insulin resistance has been found in healthy subjects for the $\mathrm{HOMA}_{\mathbb{R}}$ index being in the range of 1.25-1.41. Other authors have recorded higher $\mathrm{HOMA}_{\mathrm{IR}}$ values amounting to 2.1 (Chevenne, Trivin, Porquet, 1999) and 2.7 (Yani-Komshian, Carantoni, Abbasi, Reaven, 2000). In the present study, a significant decrease was observed in the $\mathrm{HOMA}_{\mathrm{IR}}$ index as affected by 36 workout units, from 2.7 during the first measurement to 1.8 in the second one.

Glucose metabolism disorders progressing with age are often associated with lipid accumulation in myocytes (Lowell, Shulman, 2005) and an age-related decrease in adiponection level (Haluzik, 2005). Studies have shown that the level of adiponectin, as one of the adipose tissue cytokines, decreases in the blood plasma of people with the obesity of internal organs (Kopff, Jegier, 2006). In the present study, an increase in the adiponectin concentration was observed after 36 workout units. Other studies, have yielded similar results, showing an increase in its concentration and a decrease in body mass in the women after regular physical activity (Bouassida, Chamari, Zaouali, Feki, Zbidi, Tabka, 2010; Kondo, Kobayashi, Murakami, 2006).

Leptin, among others, is responsible for the homeostasis of energy expenditure and the control and regulation of the amount of body fat (Güçlü, 2014). Studies have shown that the leptin concentration decreased during body mass reduction, while it increases with the increase of adipocyte volume. In women, as compared with men, a 2-3 times higher plasma level of this hormone, with similar BMI values, has been observed (Olszanecka-Glinianowicz, Zahorska-Markiewicz, 2008). However, it is still unclear whether a decrease in the leptin concentration is the result of body mass reduction or the result of physical activity (Jürimäe, Jürimäe, 2004; Rubin, Hackney, 2010, Lubkowska, Radecka, Bryczkowska, Rotter, Laszczyńska, Dudzińska, 2015b). In the study by Hickey et al. (1997), a decrease in the leptin concentration has been observed, with no changes in body fat mass, in women after a 12-week-long regular aerobic training. Some authors have suggested that a decrease in the leptin concentration after endurance training may be associated with a decrease in the insulin level (Jürimäe, Jürimäe, 2004). The increase of serum leptin level is directly related to the content of body fat (Güçlü, 2014). In the present study, a significant decrease in the leptin concentration was observed which significantly correlated with decreased body fat content and insulin concentration.

The concentration of ghrelin increases during fasting and decreases after ingestion of meal; it is a hormone which plays an important role in the control of hunger and satiety through energy homeostasis regulation (Cummings, Frayo, Marmonier, Aubert, Chapelot, 2004; Cederberg, Koivisto, Jokelainen, Surcel, Keinänen-Kiukaanniemi, 
Rajala, 2012). In the treatment of civilisation diseases, such as obesity, the key issue is to fully understand the hormonal control of appetite in order to apply effective therapeutic methods (Mackelvie et al., 2007; Cederberg et al., 2012). Therefore, one of the research problems being undertaken in this study was to assess the effect of increased physical activity in women on changes in the ghrelin concentration. In the present study, a significant decrease in the ghrelin concentration was observed after the training. Many studies being conducted have clearly indicated the presence of a relationship between the intensity of physical activity and the post-training level of ghrelin (King, Miyashita, Wasse, Stensel, 2010; King, Wasse, Broom, Stensel, 2010). The present study confirmed that moderateintensity exercise, which significantly decreases blood ghrelin concentration, is effective in body mass reduction for middle-aged women.

In recent years, vitamin $D_{3}$ deficiency has been shown to be significantly involved in the development of overweight and obesity in the populations of both children and adolescents and adults (Alemzadeh, Kichler, Babar, Calhoun, 2008; Foss, 2009; Niemann et al., 2011). Its deficiency may impair the effect of insulin, adversely affect glucose metabolism and other metabolic processes both in adipose tissue and in other tissues. Furthermore, recent findings disclosed a strong correlation between changes in lipid profile and level of 25(OH)D (Dziedzic, Przychodzeń, Dąbrowski, 2016; Pittas, Lau, Hu, Dawson-Hughes, 2007). Excess body fat causes the retention of fat-soluble vitamin $\mathrm{D}_{3}$ and a decrease in its serum concentration, which reduces its bio-availability (Alemzadeh et al., 2008; Foss, 2009). McGill, Stewart, Lithander, Strik, Poppitt, (2008) have shown a decrease in vitamin $D_{3}$ concentration by $0.74 \mathrm{nmol} / /$ per unit $\left(1 \mathrm{~kg} / \mathrm{m}^{2}\right)$ increase in BMl value and a decrease in vitamin $\mathrm{D}_{3}$ concentration by $0.29 \mathrm{nmol} / /$ per $1 \mathrm{~cm}$ of increased waist circumference. Moreover, recent studies prove that a physical activity could increase the use of calcidiol which emphasizes the need of its supplementation (Pilch et al., 2016). In the present study, a significant increase in the concentration of blood-circulating calcidiol was observed in the female subjects. This was probably due to an increase in its synthesis in the skin because the workouts took place in spring. According to the data of the Institute of Meteorology and Water Management in Warsaw, the total insolation in the study year for the Małopolska Province amounted to 110-120 hours in March and 140-160 hours in April and was higher by about 10-30 hours than the multi-annual average of 1971-2000. May, with a total of 200-220 hours, also had higher sunshine duration, by 10-30 hours, than the multi-annual average for this month. In the present study, an increase in the calcidiol level was observed after a 12-week-long observation period although, despite its increase, its concentration was still below the standard values. A positive correlation between final calcidiol concentration and decreased leptin concentration is evidence of its positive effect on maintaining the normal energy balance of the body.

\section{Implications for Practice and/or Policy}

The findings being obtained could be, according to the authors, the result of properly matched exercise intensity and form in suitable season. Moreover, the results of our research indicate the necessity of vitamin D supplementation despite the performance of outdoor physical activity during March-May period. The results of this study are very important for physicians and coaches, as well as for instructors who deal with physical activation and activity of middle-aged people. 


\section{Conclusions}

1. The physical activity in the form of NW exercise with individually matched training intensity regulates body composition towards increased lean body mass and decreased body fat mass.

2. Individualised and regular physical activity has a protective effect on the body, preventing adverse alterations associated with the process of ageing, the result of which is improvement in adipokine secretion profile, lipid profile and carbohydrate metabolism.

3. Sun exposure of the female subjects during a 12-week-long physical training in an open area in spring contributed to the synthesis of calcidiol but did not result in the increase of its level to the reference values, and therefore vitamin $\mathrm{D}$ supplementation should be additionally recommended in people with low calcidiol level and performing physical exercise.

4. Significant and positive changes in the biochemical indices in the female subjects that took place after a 12-week-long training programme can be an effective inhibitor in the struggle with civilisation diseases.

\section{References}

Alemzadeh, R., Kichler, J., Babar, G., Calhoun, M. (2008). Hypovitaminosis D in obese children and adolescents: relationship with adiposity, insulinsensitivity, ethnicity, and season. Metabolism, 2 (57), 183-191.

Biernat, E., Stupnicki, R., Gajewski, A. (2007). International Physical Activity Questionnaire (IPAQ). Wychowowanie Fizyczne i Sport, 1 (51), 47-54.

Bouassida, A., Chamari, K., Zaouali, M., Feki, Y., Zbidi, A., Tabka, Z. (2010). Review on leptin and adiponectin responses and adaptations to acute and chronic exercise. British Journal of Sports Medicine, 44, 620-630.

Byberg, L., Melhus, H., Gedeborg, R., Sundstrom, J., Ahlbom, A. (2009). Total mortality after changes in leisure time physical activity in 50-year-old men:35-year follow-up of population based cohort. British Medical Journal, 338-688.

Cederberg, H., Koivisto, V., Jokelainen, J., Surcel, H., Keinänen-Kiukaanniemi, S., Rajala, U. (2012). Unacylated ghrelin is associated with changes in insulin sensitivity and lipid profile during an exercise intervention. Journal of Clinical Endocrinology \& Metabolism, $76,39-45$.

Chevenne, D., Trivin, F., Porquet, D. (1999). Insulin assays and reference values. Diabetes \& Metabolism, 25, 459-476.

Chudek, J., Adamczyk, M., Nieszporek, T., Więcek, A. (2006). The adipose tissue as an endocrine organ-a nephrologists perspective. Contributions to Nephrology, 151, 70-90.

Combs, T., Berg, A., Obici, S., Scherer, P., Rossetti, L. (2001). Endogenous glucose production is inhibited by the adipose-derived protein Acrp 30. Journal of Clinical Investigation, 108, 1875-1881.

Cummings, D., Frayo, R., Marmonier, C., Aubert, R., Chapelot, D. (2004). Plasma ghrelin levels and hunger scores in humans initiating meals voluntarily without time- and food-related cues. American Journal of Physiology - Endocrinology and Metabolism, 287, E297-E304.

DeNino, W., Tchernof, A., Dionne, I., Toth, M., Adres P. (2001). Contribution of abdominal adiposity to age-related differences in insulin sensitivity and plasma lipids in healthy nonobese women. Diabetes Care, 24, 925-932.

Dobisova, M. (2004.) Atherogenic index of plasma [log(triglicerides/HDL-cholesterol)]: theoretical and practical implications. Clinical Chemistry, 50, 1113-1115.

Drygas, W., Jegier, A. (2003). Zalecenia dotyczące aktywności ruchowej w profilaktyce układu krążenia. Czynniki Ryzyka, 4/02, 76-84.

Dziedzic, E., Przychodzeń, S., Dąbrowski, M. (2016). The effects of vitamin D on severity of coronary artery atherosclerosis and lipid profile of cardiac patients. Archives of Medical Science, 6 (12), 1199-1206.

Foss, Y. (2009). Vitamin D deficiency is the cause of common obesity. Medical Hypotheses, 3 (72), 314-321.

Friedewald, W., Levy, R., Fredrickson, D. (1972). Estimation of the concentration of low-density lipoprotein cholesterol in plasma, without use of the preparative ultracentrifuge. Clinical Chemistry, 18, 499-502.

Güçlü, M. (2014). Comparing women doing regular exercise with sedentary women in terms of certain blood parameters, leptin level and body fat percentage. Collegium Antropologicum, 2 (38), 453-458. 
Hagner, W., Hagner-Derengowska, M., Wiacek, M., Zubrzycki, I. (2009). Changes in level of $\mathrm{VO}_{2} \max$, blood lipids and waist circumference in the response to moderate endurance training as a function of ovarian ageing. Menopause, 5 (16), 1009-1013.

Haluzik, M. (2005). Adiponectin and its potential in the treatment of obesity, diabetes and insulin resistance. Current Opinion in Investigational Drugs, 6, 988-993.

Haskell, W., Lee, I., Russell, R., Powell, K., Blair, S. (2007). Physical activity and public health. Updated recommendation for adults from the American College of Sports Medicine and American Heart Association. Circulation, 116, 1081-1093.

Hickey, M., Houmard, J., Considine, R., Tyndall, G., Midgette, J. (1997). Gender-dependent effects of exercise training on serum leptin levels in humans. American Physiological Society, 272, E562-E566.

Horowitz, J., Klein, S. (2000). Lipid metabolism during endurance exercise. American Journal of Clinical Nutrition, 72 (2), 558S-263S.

Hu, G., Pekkarinen, H., Hanninen, O., Tian, H., Guo, Z. (2001). Relation between commuting, leisure time physical activity and serum lipids in a Chinese urban population. Annals of Human Biology, 4 (28), 412-421.

Jürimäe, J., Jürimäe, T. (2004). Plasma leptin responses to prolonged sculling in female rowers. Journal of Sports Medicine and Physical Fitness, 44, 104-109.

Katzmarzyk, P. (2010). Physical activity, sedentarny behavior and health: paradigm paralysys or paradigm shift? Diabetes, 59 (11), 2717-2725.

King, J., Miyashita, M., Wasse, L., Stensel, D. (2010). Influence of prolonged treadmill running on appetite, energy intake and circulating concentrations of acylated ghrelin. Appetite, 3 (54), 492-498.

King, J., Wasse, L., Broom, D., Stensel, D. (2010). Influence of brisk walking on appetite, energy intake, and plasma acylated ghrelin. Medicine and Science in Sports and Exercise, 442, 485-492.

Kokkinos, P., Myers, J. (2010). Exercise and physical activity: clinical outcomes and applications. Circulation, 16 (122), $1637-1648$.

Kondo, T., Kobayashi, I., Murakami, M. (2006). Effect of exercise on circulating adipokine levels in obese young women. Endocrine Journal, 53, 189-195.

Kopff, B., Jegier, A. (2006). Physical activity and selected adipokines: adiponectin, leptin and resistin - Polish version. Polskie Archiwum Medycyny Wewnętrznej, 115, 73-84.

Kozak-Szkopek, E., Baraniak, J., Mieczkowska, J. (2006). Prevalence of coronary heart disease risk factors in the sixth decade of life - Polish version. Gerontologia Polska, 1 (14), 18-24.

Lowell, B., Shulman, G. (2005). Mitochondrial dysfunction and type 2 diabetes. Science, 307, 384-387.

Lubkowska, A., Dudzińska, W., Bryczkowska, I., Dołęgowska, B. (2015a). Body composition, lipid profile, adipokine concentration, and antioxidant capacity changes during interventions to treat overweight with exercise programme and whole-body cryostimulation. Oxidative Medicine and Cellular Longevity, 803197, 13.

Lubkowska, A., Radecka, A., Bryczkowska, I., Rotter, I., Laszczyńska, M., Dudzińska, W. (2015b). Serum adiponectin and leptin concentrations in relation body fat distribution, hematological indices and lipid profile in humans. International Journal of Environmental Research and Public Health, 9 (12), 11528-11548.

Luc, G., Bard, J., Ferrieres, J., Evans, A., Amouyel, P. (2002). Value of HDL-cholesterol, apolopoprotein A-I, lipoprotein A-I, and lipoprotein A-I/A-II in prediction of coronary heart disease: the PRIME study. Prospective Epidemiological Study of Myocardial Infarction. Arteriosclerosis Thrombosis and Vascular Biology, 22, 1155-1161.

Macaluso, A., De Vito, G. (2004). Muscle strength, power and adaptations to resistance training in older people. European Journal of Applied Physiology, 91, 450-472.

Mackelvie, K., Meneilly, G., Elahi, D., Wong, A., Barr, S. (2007). Regulation of Appetite in Lean and Obese Adolescents after Exercise: Role of Acylated and Desacyl Ghrelin. Clinical Endocrinology \& Metabolism, 92, 648-654.

Matthews, D., Hosker, J., Rudenski, A., Naylor, B., Treacker, D. (1985). Homeostasis model assessment: insulin resistance and betacell function from fasting plasma glucose and insulin concentration in man. Diabetolodia, 28, 412-419.

McGill, A., Stewart, J., Lithander, F., Strik, C., Poppitt, S. (2008). Relationships of low serum vitamin D3 with anthropometry and markers of the metabolic syndrome and diabetes in overweight and obesity. Nutrition Journal, 7 (28), 4.

Mikalacki, M., Rajdo, I., Cokorilo, N., Korovliev, D., Smajic, M. (2012). Influence of Nordic walking on body composition of elderly women. HealthMed, 2 (6), 476-482.

Morgulec-Adamowicz, N., Marszałek, J., Jagustyn, P. (2011). Nordic walking-a new form of adapted physical activity: a literature review. Human Movement, 2 (12), 124-132. 
Nes, B., Janszky, I., Wisløff, U., Støylen, A., Karlsen, T. (2013.) Age-predicted maximal heart rate in healthy subjects: The HUNT Fitness Study. Scandinavian Journal of Medicine \& Science in Sports, 23, 697-704.

Niemann, B., Chen, Y., Teschner, M., Li, L., Silber, R.E., Rohrbach, S. (2011). Obesity inducessigns of premature cardiac aging in younger patients: the role of mitochondria. Journal of the American College of Cardiology, 5 (57), 577-585.

Nilsson, G., Ohrvik, J., Lonnberg, I., Hedberg, P. (2009). Ten-year survival in 75-year old men and women: predictive ability of total cholesterol, HDL-C, and LDL-C. Current Gerontology and Geriatrics Research, 1-7.

Olszanecka-Glinianowicz, M., Zahorska-Markiewicz, B. (2008). Otyłość jako choroba zapalna. Postępy Higieny i Medycyny Doświadczalnej, 62, 249-257.

Perk, J., De Backer, G., Gohlke, H., Graham, I., Reiner, Z. (2012). European Guidelines on cardiovascular disease prevention in clinical practice. European Heart Journal, 33, 1635-1701.

Pilch, W., Tyka, A., Cebula, A., Sliwicka, E., Pilaczynska-Szczesniak, L., Tyka, A. (2016). Effects of 6-week Nordic walking training on changes in 25(OH)D blood concentration in women after 55 years of age. Journal of Sports Medicine and Physical Fitness.

Pittas, A.G., Lau, J., Hu, F.B., Dawson-Hughes, B. (2007). The role of vitamin D and calcium in type 2 diabetes. A systematic review and metaanalysis. Journal of Clinical Endocrinology \& Metabolism, 92, 2017-2029.

Pojednic, R., Ceglia, L. (2014). The Emerging Biomolecular Role of Vitamin D in Skeletal Muscle. Exercise and Sport Sciences Reviews, 2 (42), 76-81.

Polly, P., Tan, T. (2014). The role of vitamin D in skeletal and cardiac muscle function. Frontiers in Physiology, 5 (16), 145.

Reznik, Y., Morello, R., Pousse, P., Mahoudeau, J., Fradin, S. (2002). The effect of age, body mass index, and fasting triglyceride level on postprandial lipemia is dependent on apolopoproteine E. Polymorphism in subjects with non-insulin-depondent diabetes mellitus. Metabolism, 9 (51), 1088-1092.

Rubin, D., Hackney, A. (2010). Inflammatory cytokines and metabolic risk factor during growth and maturation: influence of physical activity. Medicine and Sport Science, 55, 43-55.

Scheen, A. (2005). Diabetes mellitus in the elderly: insulin resistance and/or impaired insulin secretion? Diabetes \& Metabolism, 31, 5S27-5S34.

Singh, A., Purohit, B. (2012). Physical activity, sedentary lifestyle, and obesity among Indian dental professionals. Journal of Physical Activity \& Health, 4 (9), 563-570.

Song, M., Yoo, Y., Choi, C., Kim, N. (2013). Effects of Nordic walking on body composition, muscle strength, and lipid profile in elderly women. Asian Nursing Research, 1 (7), 1-7.

Steinbacher, P., Eckl, P. (2015). Impact of oxidative stress on exercising skeletal muscle. Biomolecules, 2 (5), 356-377.

Tschentscher, M., Niederseer, D., Niebauer, J. (2013). Health benefits of nordic walking. A systematic review. American Journal of Preventive Medicine, 1 (44), 76-84.

Wren, A., Small, C., Ward, H., Murphy, K., Dakin, C. (2000). The novel hypothalamic peptide ghrelin stimulates food intake and growth hormone secretion. Endocrinology, 141, 4325-4328.

Yani-Komshian, H., Carantoni, M., Abbasi, F., Reaven, G. (2000). Relationship between several surrogate estimation of insulin resistance and quantification of insulin-mediated glucose disposal in healthy non-diabetic volunteers. Diabetes Care, 23, 171-175.

Cite this article aS: Tota, Ł., Pilch, W., Piotrowska, A., Pałka, T., Pilch, P. (2017). The Effect of 12-week-long Nordic Walking Exercise on Body Composition, Changes in Lipid and Carbohydrate Metabolism Indices, Concentration of Selected Adipokines and Calcidiol in Healthy Middle-aged Women. Central European Journal of Sport Sciences and Medicine, 4 (20), 69-80. DOI: 10.18276/ cej.2017.4-08. 